\title{
Retraction Note to: Cerebrospinal fluid ferritin in glioblastoma: evidence for tumor synthesis
}

\author{
Yoshihiro Sato $^{1} \cdot$ Yoshiaki Honda $^{1} \cdot$ Takeshi Asoh $^{1} \cdot$ Kotaro Oizumi $^{2} \cdot$ Yuki Ohshima $^{3} \cdot$ Eiichiro Honda $^{3}$
}

Published online: 29 July 2019

(c) Springer Science+Business Media, LLC, part of Springer Nature 2019

\section{Retraction to: Journal of Neuro-Oncology (1998) 40(1):47-50 https://doi.org/10.1023/A:1006078521790}

The Editor-in-Chief has retracted this article [1]. An investigation by Kurume University has not been able to establish what the appropriate authorship should be because one of the authors, Yoshihiro Sato, is now deceased. As the appropriate authorship cannot be determined the Editor-in-Chief no longer has confidence in this article. Kurume University has also stated that it has not been possible to verify the data presented as none of the research material is available for investigation. We have not been able to contact Yoshiaki
Honda, Takeshi Asoh, Kotaro Oizumi, Yuki Ohshima and Eiichiro Honda about this retraction.

\section{Reference}

1. Sato Y, Honda Y, Asoh T, Oizumi K, Ohshima Y, Honda E (1998) Cerebrospinal fluid ferritin in glioblastoma: evidence for tumor synthesis. J Neurooncol 40:47-50. https://doi. org/10.1023/A:1006078521790

Publisher's Note Springer Nature remains neutral with regard to jurisdictional claims in published maps and institutional affiliations.
The original article can be found online at https://doi. org/10.1023/A:1006078521790.

1 Department of Neurology, Futase Social Insurance Hospital, Iizuka, Japan

2 Department of Internal Medicine, Kurume University School of Medicine, Kurume, Japan

3 Department of Neurosurgery, Ohshima Hospital, Kitashigeyasu, Japan 